\title{
Determination of environmental effects on production efficiency of agricultural demonstration zones
}

\section{Authors Info \\ S. Wu', Y. Zhang ${ }^{1}$ and Y. Quan ${ }^{2 *}$ \\ ${ }^{1}$ College of Economics and Management, Shandong University of Science and Technology, Qingdao, 266 590, China \\ ${ }^{2}$ College of Humanities and Law, Shandong University of Science and Technology, Qingdao, 266590 , China}

\section{*Corresponding Author Email :} everwsj@163.com

\section{Edited by}

Prof. Ahmed Jalal Khan Chowdhury

\section{Reviewed by \\ Dr. Keqing Li \\ Dr. Dan Li}

\begin{abstract}
Aim: The present study aimed to solve the problems that the production efficiency of national modern development area, and the influence of environment effect on agricultural production efficiency.

Methodology: Based on the input-output data of 51 modern agricultural demonstration zones in Shandong Province in 2015, a three-stage DEA model was used for study. In the first stage, the traditional efficiencies were calculated depended on the original inputs and outputs, and input slacks were evaluated. In the second stage, the impacts of external environment and statistic noise were removed by SFA model, and inputs were adjusted. At last, the third stage efficiencies were calculated depended on the result of SFAmodel.
\end{abstract}

Results: The results show that under the influence of environment effect and random error factors, the agricultural production efficiency measured before and after the adjustment of input factors had changed obviously. Farmers' income level, urbanization level, financial support level and rural informatization level have significant influence on the input factor redundancy. Compared with the results of the first and third stage DEA model, the average technical efficiency of demonstration zone increased from 0.79 to 0.83 , the average pure technical efficiency increased from 0.90 to 0.91 , and the average SE increased from 0.88 to 0.90 .

Interpretation: According to the best conditions to improve the efficiency of agricultural production, the demonstration zones should combine their own characteristics and policy-driven force, make rational allocation of agricultural production factors, improve the level of agricultural technology, promote the reform of production methods, and optimize the development environment.

Keywords : Agricultural production efficiency, Environment effect, Modern agricultural demonstration zone, Three-stage DEA

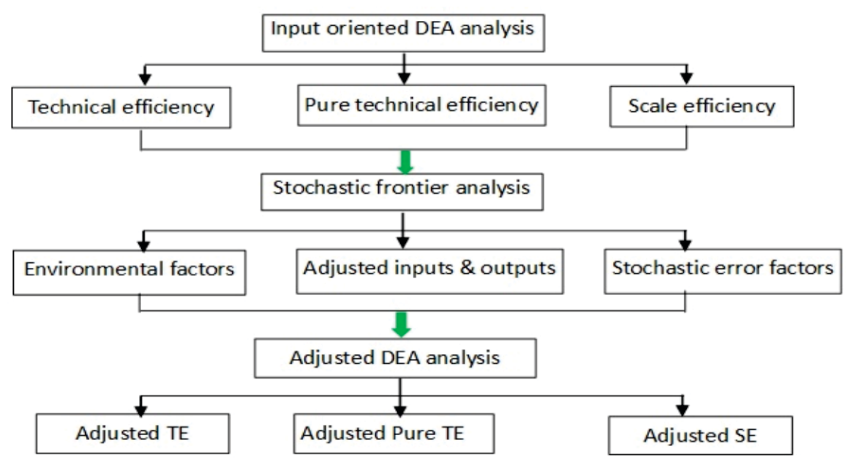

Citation: Wu, S., Y. Zhang and Y. Quan: Determination of environmental effects on production efficiency of agricultural demonstration zones. J. Environ. Biol., 40, 486-496 (2019) 


\section{Introduction}

China is facing a critical period of agricultural modernization nowadays. In the process of agricultural development, there are serious contradictions between people and land, tight resource constraints, rising agricultural costs, "dual" segmentation of urban and rural structure, hence the agricultural modernization must take gradient advancement instead of step-by-step approach (Ismail and Haron, 2017; Jamal et al., 2018). To explore the effective mode of agricultural modernization and to accelerate the "four transformation and upgrading" of agricultural production mode, resource utilization mode, operation mode and industrial structure, the Ministry of Agriculture launched the construction of national modern agricultural demonstration zones in November 2009, promoting the development of agricultural modernization with the policy of "whole county system". By the end of 2015, the Ministry of Agriculture has identified 283 state-level modern agricultural demonstration zones covering a total area of 1.27 million square kilometers. The administrative level covers 31 provinces and 236 counties, accounting for $13 \%$ of the national territorial area, and food production topped $40 \%$.

Different from the previous agricultural demonstration zones, national modern agricultural demonstration zones have a high starting point under the policy-driven development of modern agriculture, with high standards and high levels and lead the development of China's modern agriculture in the agricultural mode reform, efficient use of resources, agricultural technological progress, industrial layout optimization, institutional mechanism innovation and other aspects (Gao et al., 2016; Nasri and Bouaicha, 2017; Ayaz et al., 2018). According to Report on the Monitoring and Evaluation of Construction Level of National Modern Agricultural Demonstration Zone in 2015 issued by the Ministry of Agriculture, in 2014, the demonstration zones achieved remarkable results in improving production conditions, strengthening scientific and technological support, ensuring supply capacity, promoting industrial management and promoting ecological and environmental protection. The degree of agricultural modernization reached $94.9 \%$. However, there are many differences in the agricultural development base, ecological type, environmental capacity and resource carrying capacity (Samad et al., 2017; Abbas et al., 2018). The overall level of development is not balanced, farmers are under pressure from increasing income, with prominent issues as low agricultural production income, low level of scientific and technological content and standardization of agricultural products, and low level of social services (Radmanfar et al., 2017; Chuanlei et al., 2018).

Agricultural modernization development relies on policy, science and technology, and input, but ultimately depends on science and technology. As the basic conditions of the demonstration zones are generally better than other regions, governments at all levels put forward support policies to strengthen the input of capital, technology, system and other elements, making the demonstration zones more competitive (Azratul et al., 2017; Howlader et al., 2018). But if this competitiveness comes mainly from policy and input, rather than from technological progress and production efficiency increase, it is contrary to the original intention and will make it difficult for agricultural modernization to play a good role of technical leadership and innovation demonstration. Some scholars have focused on the impact of development basis and policy on the competitive advantages of the demonstration zone. Jiang used factor analysis for the evaluation of the first batch of 51 countries identified as agricultural demonstration zones, and held that demonstration zones with a higher level of comprehensive development are generally the areas with more developed county economy, and these areas have better organization of farmers, agricultural science and technology promotion and use, and agricultural mechanization applications used DID model to compare the development differences between the demonstration zone and non-demonstration zone, and held that the improvement of competitiveness of demonstration zone was mainly due to policy driving rather than by self-development trend (Gao et al., 2016; Hashemi, 2017).

Since there are few studies on the technical efficiency of demonstration zone development, and most of the sample data are inter-provincial, the interference of environment effects and random error will make it difficult to accurately understand the production efficiency and the main problems of demonstration zones. Therefore, this study uses three-stage DEA model for evaluation of technical efficiency of 51 national modern agricultural demonstration zones in Shandong Province set up in 2015, while avoiding the impact of natural conditions, regional economic level and policy differences as far as possible, so as to clarify the changes of pure technical efficiency, SE and comprehensive technical efficiency of demonstration zones under policy driving, and to conduct a detailed analysis of the impact of environmental factors.

\section{Materials and Methods}

Review of research methods: As an important source of agricultural economic growth, the measurement and evaluation of agricultural production efficiency has been paid much attention. Others used C-D production function and Solow residual method to estimate the agricultural production efficiency in China (Lin, 1992; Wen, 1993; Zheng, 2009; Ashraf et al., 2017). Researchers have also used SFA to measure and analyze the technical efficiency of China's agricultural production during different time periods (Kuang, 2012; Farrell, 1957; Tariq et al., 2017). With continuous improvement and maturity of efficiency measure method, Data Envelopment Analysis (DEA) has been paid much attention because of its unit invariance, unique advantages of without the need to preset the production function in advance and the multiple input/output. An early analysis of agricultural 
production efficiency using DEA, was made and "default production function" was replaced with "non-default production function" and studied with the agricultural productivity in the United Kingdom combined with the mathematical programming model (Farrell, 1957; Hanley and Oglethorpe, 1998). Subsequently, the DEA model was used to calculate the technical efficiency of Swedish dairy farms and Thai farms (Krasachat, 2009; Hasanov and Nomman, 2011; Fahim and Sathi, 2018). In other studies, DEA method was employed to analyze agricultural production efficiency and related influencing factors detailed of Uzbekistan, Indian states and Brazilian states (Theodoridis, 2014; Ray and Ghose, 2014; Souza and Gomes, 2015). Domestically, some researchers used DEA to measure the agricultural production efficiency in different periods of time, and found that the degree of education, financial support and farmers' net income have a significant impact on productivity growth (Fang, 2010; He, 2015; Chen, 2016).

A three-stage DEA model was proposed by combining DEA and Stochastic Frontier Approach (SFA), by eliminating the environment effects and random errors, the economic efficiency of each decision-making unit can be measured more accurately, which cannot be achieved by the one-stage DEA model and twostage DEA model (Banker and Morey, 1986; Fare et al., 1993; Fried et al., 2002), and has been widely used in the measurement of efficiency in multiple areas, such as carbon emission and regional innovation (Liu, 2017; Tian, 2017). Among them, Jiao (2013) used the three-stage DEA model to study the agricultural production efficiency of 17 cities in Shandong Province in 2011 and found that SE was the main factor restricting the overall efficiency level. At the same time, Liu (2015) used this method to evaluate and analyze the organic agricultural production efficiency of Yang County, Shanxi. The study suggested that organification can promote the improvement of agricultural production efficiency, which is less effective compared with pure technical efficiency and scale efficiency.

Building of three-stage DEA model: Compared with the traditional DEA model and SFA model, the three-stage DEA model can eliminate the redundancy caused by the environment effect, so that the estimated efficiency value more truly reflects the internal management level of DMU, so as to measure the relationship between input and output efficiency more accurately. The first stage: use traditional DEA model for efficiency analysis and calculate the original efficiency value and input slack situation of decision-making units. As this paper takes into account the actual scale of returns in the efficiency measure, hence BCC basic planning is selected.

$$
\begin{aligned}
& \min _{\theta, \lambda}\left[\theta-\varepsilon\left(e^{t} s^{-}+e^{t} s^{+}\right)\right] \\
& \left\{\begin{array}{l}
s . t . \sum_{j=1}^{n} \lambda_{j} x_{i j}+s=\theta x_{i k} \\
\sum_{j=1}^{n} \lambda_{j} y_{i j}-s^{+}=y_{r k} \\
\sum_{i=1}^{n} \lambda_{i}=1, \lambda_{i} \geq 0 ; s \geq 0 ; s^{+} \geq 0
\end{array}\right.
\end{aligned}
$$

Where, $i=1,2 \ldots m ; j=1,2 \ldots q ; r=1,2, \ldots n . n, m, q$ are the number of decision-making units, the number of input and output variables. $x_{i j}$ is the $f^{\text {th }}$ input element of the ith decision-making unit, $y_{i r}$ is the $r^{\text {th }}$ output element of the $i^{\text {th }}$ decision-making unit, $\theta$ is the effective value of the decision-making unitDMU. The results are:

$$
\left\{\begin{array}{lr}
\theta=1, s=s^{+}=0 & \text { DMU is effective } \\
\theta=1, s \neq 0 \text { or } s^{+} \neq 0 & \text { DMU is weakly effective } \\
\theta \neq 1 & \text { DMU is not effective }
\end{array}\right.
$$

Second stage: SFA was used for analysis. A reasonable environment variable was selected as an explanatory variable, a multiple linear regression model was established for the input redundant variable separated from the DEA model, as shown in equation (3). Then, it was combined with the regression results of SFA model, the input variable values were adjusted accordingly, so that all DMUs were adjusted to the same environmental conditions and error states, so as to calculate the actual input value after removing environmental factors and random errors.

$$
S_{i k}=f^{i}\left(Z_{k} ; \beta i\right)+v_{i k}+u_{i k}
$$

Where, $S_{i k}$ represents the slack variable of the $k$ th input of the ith decision-making unit; $Z_{k}=\left(Z_{1 k}, Z 2_{k} \ldots Z_{p k}\right)$ represents the observed value of the $k^{\text {th }}$ inefficient environment variable. $f^{\prime}\left(Z_{k} ; \beta^{i}\right)$ indicates the effect of environment variables on the $S_{i k}$ input difference value. Generally, $f^{i}\left(Z_{k} ; \beta^{i}\right)=Z_{k} \beta^{i}$. $\beta^{i}$ is the parameters of the environment variable that needs to be estimated, $v_{i k}$ is a random error term, $v_{i k}-\left(0, \sigma_{i}^{2}\right), u_{i k}$, is the non-negative random variable that manages inefficiency in the production process. Supposing that it is subject to truncated normal distribution, ie $u_{i k}\left(\mu^{i}, \sigma_{u i}^{2}\right), v_{i k}$ and $u_{i k}$ are independent of independence. According to equation (3), the estimate is taken into the formula for adjusting the input:

$$
\hat{x}_{i k}=x_{i k}+\left[\max _{k}\left\{z^{k} \beta^{i}\right\}-z^{k} \hat{\beta}^{i}\right]+\left[\max _{k}\left\{\hat{V}_{i k}\right\}-\hat{V}_{i k}\right]
$$

In equation (3), $\left[\max _{k}\left\{z^{k} \beta^{i}\right\}-z^{k} \beta\right]$ indicates the adjustment of all decision-making objects to the same worst production environment, $\left[\max _{k}\left\{V_{i k}\right\}-V_{i k}\right]$ indicates the adjustment of the random error term. The purpose is to make both the environmentally favorable DMU and environmentally unfavorable DMU under a fair environment level.

Third stage: Adjusted DEA model was used. BCC model was used to re-conduct an efficiency evaluation of the original output data and the factor input value adjusted by SFA model, the environmental factors and random error interference was filtered, so as to get more objective and fairer DMU real efficiency values.

Research material and data specification: Modern agriculture is a new type of agriculture which integrates economic development, social production and eco-environment functions. By integrating a large amount of modern human capital and science and technology to realize the unity of economic, social 
and ecological benefits, the index evaluation should cover the relevant content. This paper referred to the system and related indicators of "monitoring and evaluation system of the construction level of national modern agricultural demonstration zones", and learned the selection of indicators from related scholars, and selected 4 output variables, 10 input variables and 4 environment variables to build the evaluation index system of the production efficiency of modern agricultural demonstration zones. Where the output variables include the total output value of agriculture, forestry, animal husbandry and fishery, certification proportion of the three grades of drugs of agricultural product, the proportion of agricultural products processing industry output value, and specific gravity index of the added value of agriculture, forestry, animal husbandry and fishery services; the input variables include the number of employed persons in the primary industry that reflect the labor input, the area of the crops that are reflected in the land input, the moderate scale of the land management, the agricultural and forestry affairs expenditure, the agricultural energy input, the agricultural fertilizer input, the level of agricultural mechanization that reflect the agricultural science and technology input, the level of farmers skills, the total number of agricultural extension service personnel that reflect the agricultural management input in the proportion of farmers to participate in cooperatives as well as other indicators. Taking into account the impact of environmental factors, while selecting the farmers' income level, urbanization level, financial support, rural informatization level as the environment variable indicators. Index names and meanings are as shown in Table 1.

\section{Results and Discussion}

BCC model estimation of the production efficiency: Based on the BCC model, MaxDEA software was used to evaluate the production efficiency level and the return to scale of 51 modern agricultural demonstration zones in Shandong Province in 2015. The results are shown in Table 2.

It can be seen from Table 2, the average TP of 51 modern agricultural demonstration zones in Shandong Province in 2015 was 0.79 , average PTE of 0.90 , and average SE of 0.88 . TE reflects optimal allocation between input and output, mainly measuring the overall efficiency of decision-making units; PTE reflects the effective use of input on the basis of established output; SE reflects the difference between production boundary production and optimal size production under established input. From the first stage of empirical results, PTE was greater than SE, indicating that technical factors play a leading role in the agricultural production efficiency of demonstration zone of Shandong Province, SE is in a secondary position. At the same time, return to scale reflects the relationship between changes in the scale of production and the resulting changes in production during agricultural production. In the results, 13 counties in the frontier of TP remained the same scale income, the scale of income of Rushan, Gaotang and other eight counties increased, the remaining 28 counties decreased. As the above results include the impact of environmental factors and random factors, and cannot truly reflect the agricultural production efficiency situation of demonstration zones of Shandong Province, SFA model is required for further adjustment and measurement.

Productivity and environment effect analysis based on SFA model: The slack amount of labor, land, material, technology and management obtained from the first stage are taken as dependent variables, the SFA regression model is constructed by using the income level, urbanization level, financial support and rural informatization level as independent variables. Using Frontier 4.1 software, the maximum likelihood estimation method was used to analyze the SFA regression model. In the estimation results, if the regression parameter of the environment variable is significantly positive, it indicates that the increase of the environment variable will cause the input slack of decisionmaking unit to increase, resulting in the waste of elements and low efficiency of production. On the contrary, if the regression parameter of the environment variable is significantly negative, it indicates that the increase of environment variable reduces the amount of input slack in decision-making unit, i.e., to a certain extent, to avoid the waste of elements and improve production efficiency. Model regression results are shown in Table 3.

Table 3 shows that the four-environment variable-farmers' income level, urbanization level, financial support level and rural informatization level had significant effect on most of the amount of slack. However, all environment variables did not have a significant impact on the moderate scale of land management and the proportion of farmers to participate in cooperatives, indicating that only the properties of positive and negative coefficients can explain the impact direction, and that these two indicators are under great impact of land transfer system and the level of development of local cooperatives and other factors, which cannot be effectively reflected in the input and output. In Table 3, the larger the proportion of variance of input slack caused by inefficiency of management in the total variance, the greater the effect of management inefficiency on the generation of slack variable. The values of main input slack were close to 1 , indicating that some of these inputs were inefficient in the production process; the input slack of agricultural energy consumption and fertilizer use was close to 0 and was significant at $1 \%$ level, indicating that agricultural diesel and fertilizer input were mainly caused by random factors. Therefore, it is necessary to evaluate the production efficiency, to use SFA regression model to decompose various types of input slack in the production process, and to eliminate the input slack caused by inefficiency of management and to eliminate the interference of external environment effects and random factors. The following are the input redundancy analysis of four environment effects on labor, land, material, technology and management.

The impact of farmers' income. The calculation results 
Table 1 : Index selection and specification

\begin{tabular}{|c|c|c|c|}
\hline \multirow{2}{*}{$\begin{array}{l}\begin{array}{l}\text { Variable } \\
\text { classification }\end{array} \\
\text { Output } \\
\text { variables }\end{array}$} & Indicators & \multicolumn{2}{|c|}{ Symbols Calculate formula and meaning } \\
\hline & $\begin{array}{l}\text { (1) The total output value of agriculture, } \\
\text { forestry, animal husbandry and fishery }\end{array}$ & $O P_{1}$ & Reflecting the indicators of added agricultural output value \\
\hline & $\begin{array}{l}\text { (2) Certification proportion of the three grades } \\
\text { of drugs of agricultural product }\end{array}$ & $\mathrm{OP}_{2}$ & $\begin{array}{l}\text { (Green food production + organic food production + pollution-free } \\
\text { agricultural production) / the total amount of local edible agricultural } \\
\text { products, reflecting the quality, ecology, safety level and standardized } \\
\text { production level of agricultural products. }\end{array}$ \\
\hline & $\begin{array}{l}\text { (3) The proportion of agricultural products } \\
\text { processing industry }\end{array}$ & $\mathrm{OP}_{3}$ & $\begin{array}{l}\text { The total output value of agricultural products processing industry/ } \\
\text { agricultural output value, reflecting the level of agricultural } \\
\text { industrialization and deep processing of agricultural products. }\end{array}$ \\
\hline & $\begin{array}{l}\text { (4) Percentage of added value of agriculture, } \\
\text { forestry, animal husbandry and fishery } \\
\text { service industry }\end{array}$ & $\mathrm{OP}_{4}$ & $\begin{array}{l}\text { Added value of agriculture, animal husbandry and fishery service } \\
\text { industry/agriculture, forestry, animal husbandry and fishery, reflecting } \\
\text { the level of agricultural social services }\end{array}$ \\
\hline \multirow[t]{10}{*}{ Input variables } & $\begin{array}{l}\text { (5) Number of employed persons in the } \\
\text { primary industry }\end{array}$ & $\mathbb{I P}_{1}$ & Reflecting the level of agricultural labor input \\
\hline & (6) Crop acreage & $\mathbb{I P}_{2}$ & Reflecting the level of agricultural land input \\
\hline & (7) Moderate scale management level of land & $\mathbb{P}_{3}$ & Reflecting the scale of agricultural operations \\
\hline & $\begin{array}{l}\text { (8) Agriculture, forestry and water affairs } \\
\text { expenditure }\end{array}$ & $I P_{4}$ & Reflecting the status of fiscal and agricultural production expenditure \\
\hline & (9) Agricultural energy input & $\mathbb{I P}_{5}$ & $\begin{array}{l}\text { Reflecting the agricultural energy consumption by annual amount of } \\
\text { agricultural diesel (equivalent value) }\end{array}$ \\
\hline & (10) Fertilizer input & $I_{6}$ & $\begin{array}{l}\text { Calculated by the amount of chemical fertilizers (pure amount) used in } \\
\text { the actual production process in this year }\end{array}$ \\
\hline & (11) Agricultural mechanization level & $\mathbb{I P}_{7}$ & $\begin{array}{l}\text { Crop farming, machine sowing, machine harvest situation, reflecting the } \\
\text { level of agricultural equipment }\end{array}$ \\
\hline & (12) Farmers' skill level & $\mathbb{I P}_{8}$ & $\begin{array}{l}\text { The number of agricultural labor force with professional certificate/the } \\
\text { number of persons employed in the primary industry, reflecting the level } \\
\text { of agricultural labor education. }\end{array}$ \\
\hline & $\begin{array}{l}\text { (13) Total number of agricultural extension } \\
\text { service personnel }\end{array}$ & $\mathbb{I P}_{9}$ & Reflecting the level of agricultural science and technology services \\
\hline & $\begin{array}{l}\text { (14) The proportion of farmers to participate } \\
\text { in cooperatives }\end{array}$ & $I P_{10}$ & Reflecting the degree of agricultural production organization \\
\hline
\end{tabular}

Environment in cooperatives

variables

(15) Farmers' income level

Env $_{1}$

Expressed in terms of the per capita net income of farmers, the increase in farmer income will lead to an increase in agricultural input, which will lead to an increase in agricultural production efficiency.

(16) Urbanization level

$E_{2} \quad$ Demonstration zone's urban population/total population, urbanization will have an impact on per capita arable land, agricultural factors of production and resource allocation.

(17) Financial supportlevel

$E_{3} \quad$ Added value of agriculture, forestry and water affairs expenditure / agriculture, forestry, animal husbandry and fishery reflects the level of financial expenditure for supporting agriculture and national support for agriculture

(18) Rural informatization level

Env $_{4} \quad$ Expressed in terms of the number of computers per 100 households, the promotion of rural informatization will help farmers gain advanced knowledge and broaden the field of agricultural production.

show that the slack variable of farmers' income level against the input of labor, land, agriculture, forestry and water affairs expenditure passed varying degrees of significance tests. Where, the influence coefficient of slack variable of labor, land, agricultural energy consumption and management input was positive, indicating that the increase in farmers' income level would increase the input redundancy of these elements; at the same time, the influence coefficient of farmers 'income level on the slack variable of technology input and material input (except for agricultural energy consumption) was negative, indicating that the increase in farmers' income will lead to reduction of input in these factors. The possible reason is that with increase in farmers' income level, the importance of agricultural production and comparative benefits decline. The negative effects of agricultural 
Table 2: Technical efficiency, pure technical efficiency and SE values of agricultural production in demonstration zones

\begin{tabular}{|c|c|c|c|c|c|c|c|c|c|}
\hline Country & TE & PTE & SE & $\begin{array}{l}\text { Returns to } \\
\text { scale }\end{array}$ & Country & TE & PTE & SE & $\begin{array}{l}\text { Returns to } \\
\text { Scale }\end{array}$ \\
\hline Wendeng & 1.00 & 1.00 & 1.00 & - & Decheng & 0.83 & 0.91 & 0.92 & IRS \\
\hline Rongcheng & 1.00 & 1.00 & 1.00 & - & Yucheng & 0.67 & 0.75 & 0.89 & DRS \\
\hline Rushan & 0.84 & 0.95 & 0.88 & IRS & Laoling & 1.00 & 1.00 & 1.00 & - \\
\hline Dongying & 0.98 & 1.00 & 0.98 & IRS & Linyi & 0.73 & 0.89 & 0.82 & DRS \\
\hline Hekou & 1.00 & 1.00 & 1.00 & - & Pingyuan & 0.61 & 0.78 & 0.77 & DRS \\
\hline Guangrao & 0.41 & 0.63 & 0.66 & DRS & Xiajin & 0.69 & 0.84 & 0.82 & DRS \\
\hline Lijin & 0.76 & 0.97 & 0.78 & DRS & Wucheng & 0.76 & 0.81 & 0.94 & DRS \\
\hline Daiyue & 1.00 & 1.00 & 1.00 & - & Qingyun & 0.60 & 0.74 & 0.81 & DRS \\
\hline Yishui & 1.00 & 1.00 & 1.00 & - & Ningjin & 0.79 & 0.93 & 0.85 & IRS \\
\hline Zhangqiu & 0.71 & 0.89 & 0.80 & DRS & Qihe & 0.69 & 0.74 & 0.93 & DRS \\
\hline Guanxian & 1.00 & 1.00 & 1.00 & - & Tengzhou & 0.65 & 0.76 & 0.85 & DRS \\
\hline Xinxian & 0.74 & 0.79 & 0.93 & DRS & Shizhong & 0.73 & 0.95 & 0.77 & DRS \\
\hline Yanggu & 0.73 & 0.85 & 0.86 & DRS & Shanting & 0.69 & 0.80 & 0.87 & IRS \\
\hline Dong'e & 0.75 & 0.90 & 0.83 & DRS & Taierzhuang & 0.74 & 0.81 & 0.92 & DRS \\
\hline Chiping & 0.79 & 0.91 & 0.87 & DRS & Xuecheng & 1.00 & 1.00 & 1.00 & - \\
\hline Gaotang & 0.90 & 0.97 & 0.92 & IRS & Pingdu & 0.99 & 1.00 & 0.99 & IRS \\
\hline Dongchang & 0.70 & 0.85 & 0.83 & DRS & Laixi & 1.00 & 1.00 & 1.00 & - \\
\hline Linqing & 0.59 & 0.88 & 0.67 & DRS & Huangdao & 0.78 & 0.92 & 0.85 & DRS \\
\hline Juxian & 0.82 & 0.87 & 0.94 & IRS & Jiaozhou & 1.00 & 1.00 & 1.00 & - \\
\hline Linzi & 0.75 & 0.95 & 0.80 & DRS & Jimo & 1.00 & 1.00 & 1.00 & - \\
\hline Juye & 0.68 & 0.91 & 0.74 & DRS & Bincheng & 1.00 & 1.00 & 1.00 & - \\
\hline Shouguang & 1.00 & 1.00 & 1.00 & - & Boxing & 0.69 & 0.86 & 0.81 & DRS \\
\hline Fangzi & 0.73 & 0.91 & 0.80 & IRS & Zhaoyuan & 0.80 & 0.92 & 0.86 & DRS \\
\hline Changle & 0.64 & 0.75 & 0.86 & DRS & Kenli & 0.72 & 0.91 & 0.79 & DRS \\
\hline Zhucheng & 0.76 & 0.97 & 0.79 & DRS & Laizhou & 0.73 & 0.76 & 0.96 & IRS \\
\hline Lingxian & 0.68 & 0.89 & 0.77 & DRS & Average Value & 0.79 & 0.90 & 0.88 & - \\
\hline
\end{tabular}

Note: TE, PTE and SE respectively represent the technical efficiency, pure technical efficiency and SE, Where TE = PTE. In the case of return to scale, the IRS has an increase in the return to scale, DRS has a decrease in the return to scale, - for the same return to scale

labor increase, farmers tend to select more extensive and laborsaving mode of production, paying attention to agricultural machinery, fertilizer, pesticides and other material input, reducing labor input and land input. The problem of continuous decline of cultivated land abandonment and the repeated cropping index in the eastern region has fully explained contradiction between the increase of farmer's income and decrease of land input and labor input. At the same time, the increase in income level also allows farmers to have sufficient financial strength to improve the technical level as well as agricultural production environment, thus contributing to the promotion of agricultural information input and agricultural technology input.

The impact of urbanization level. From Table 3, the slack variable coefficient of urbanization level for the majority of the input variables was negative, in particular, the input redundancy of land input, the appropriate scale of land management and the comprehensive mechanization level of crop cultivation were at significant $5 \%$ and $1 \%$, indicating that the improvement of urbanization level helps to reduce the input redundancy of these factors and to improve the efficiency of input. The slack variable coefficient of urbanization level for agriculture, forestry and water affairs expenditure was positive, indicating that it may exacerbate the input redundancy of element. Rural urbanization and agricultural industrialization, farmers non-agricultural transformation are collaborative process. With the upgrading of urbanization level, a large number of rural labor force transfer from rural areas and farms to urban sector and non-agricultural industries.

Land transfer expands the scale of agricultural land management, which creates conditions for increase of land input and moderate scale operation, and also helps to promote manpower saving and agricultural mechanization level improving. However, while transferring rural labor force, urbanization adversely affects fine agriculture requiring high consumption of water and fertilizer and fine drip irrigation, to a certain extent, reducing the efficiency of agriculture, forestry and water affairs expenditure.

The impact of financial support level. The input redundancy of increase of financial support level for labor input, land input, agriculture, forestry and water affairs expenditure and the comprehensive mechanization level of crop cultivation was 


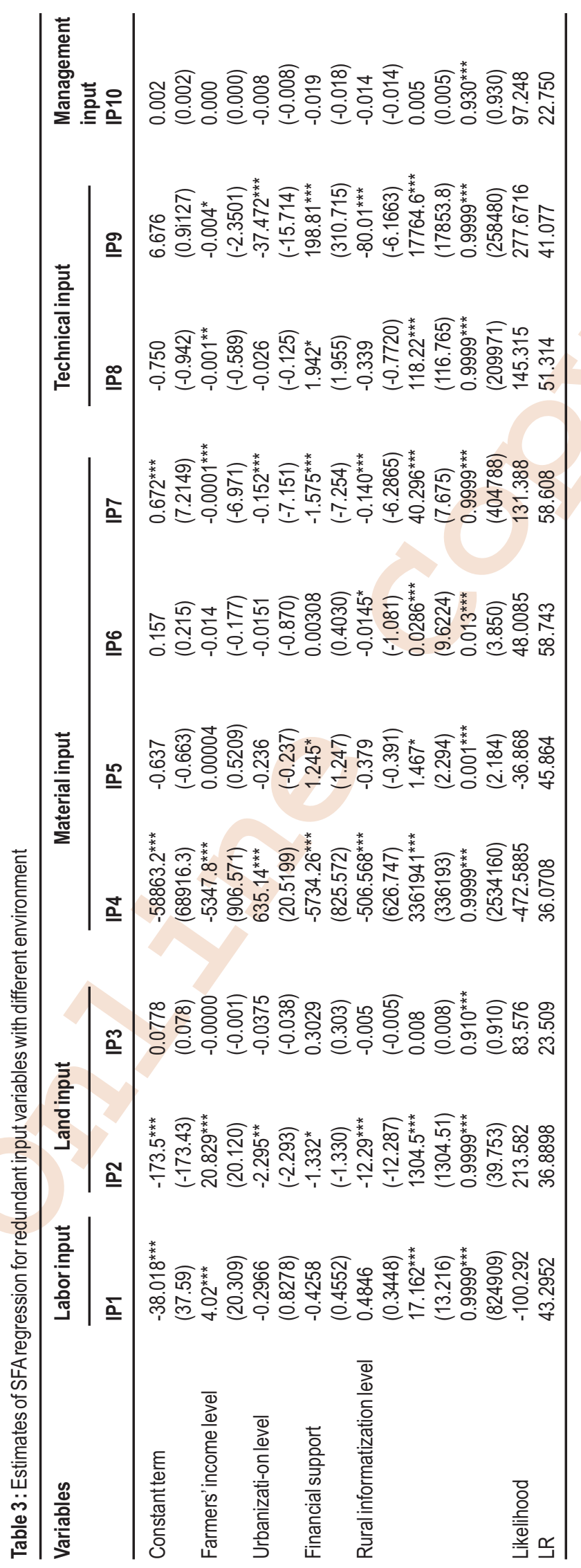

* Journal of Environmental Biology, Special issue, May 2019 * 
negative and strongly significant, indicating that the increase in financial support would reduce these input factor redundancy and help to improve efficiency; but the impact of financial support level on agricultural material input (except for agriculture, forestry and water affairs expenditure) and slack variables of technical input was positive, and both have passed a 10\% significance test, indicating that increased financial support would result in redundancy of these factors. The reason may lie in various financial subsidies for agricultural production, such as direct subsidies for grain production, subsidies for seed subsidies, subsidies for agricultural machinery purchase and minimum purchase price of agricultural products, which increased the comparative benefits of agricultural production and helped to increase agricultural labor, land and mechanical input. But the financial subsidy policy may also have a crowding-out effect, to a certain extent, reducing the farmers' own input; and the increased production scale and mechanization caused extensive production and reduced technical input. In addition, the national financial subsidies in agricultural technology are often associated with specific technical assistance, such as soil testing and fertilizer subsidies, animal epidemic prevention subsidies, promotion of new varieties and subsidies for grain and sugar, which can greatly improve the efficiency of use of technology funds, reduce waste of funds caused by the farmers' spontaneous input in technology, and increase input redundancy to a certain extent.

The impact of rural informatization level. The regression coefficient of increase in this variable was negative for the land, material, technology and management input, and was significant at $10 \%$ significance level, which could reduce the relevant input redundancy. But the regression coefficient of increase in rural informatization level was positive for labor input redundancy, which means that it may exacerbate labor input redundancy. This shows that when the rural informatization level was promoted, agricultural producers obtained a variety of production and sales information more easily, improving the scientific decision-making elements while improving resource allocation efficiency. However, promotion of agricultural informatization level enhanced agricultural modernization and the level of agricultural technology, it also exacerbates the surplus of agricultural labor, resulting in increased labor force input.

Production efficiency estimate after elimination of environment effects: In order to normalize the operating environment of agricultural demonstration zones, so as to measure the level of production efficiency more accurately, the input redundancy generated from inefficient management should be eliminated according to the impact of environment variables on input slack calculated the second stage. And the adjusted input is used as the new input variable to recalculate the efficiency value. The production efficiency level of each demonstration zone after the third-stage DEA analysis using the adjusted input variables is shown in Table 4.
By comparing Table 2 and Table 4 , it can be seen that the efficiency indicators of agricultural production efficiency in the demonstration zone have increased after adjustment of input factors. Where, the average TP rises from 0.79 to 0.83 , the average PTE rises from 0.90 to 0.91 , and the average SE rises from 0.88 to 0.90 . At the same time, the return to scale level of agricultural production in the demonstration zone has also changed from decreasing to increasing, indicating that the increasing proportion of input factors is smaller than that of output under similar same conditions.

After eliminating the environment effect and random factors, the counties and cities can be divided into four categories according to the comprehensive efficiency of agricultural production. The first category is the production frontier region with decision-making unit efficiency value of 1.00 , a total of 15 counties, accounting for about $29.41 \%$. In contrast to the first stage, the number of counties and cities in the technical forefront increased by 2 from 13. 11 counties and cities including Wendeng, Rongcheng, Jimo have always been in the TP front side, indicating that these counties have better agricultural production efficiency; Dongying, Wucheng, Pingdu, Gaotang County rose to the forefront of efficiency in the third stage, indicating that the four counties and cities are relatively efficient agricultural production in the homogeneous environment after eliminating environmental factors and random effects, entering production frontier; while Laixi and Jiaozhou are no longer located in the TP frontier due to decrease in SE and PTE. The second category is the agricultural production efficient region with decision-making unit efficiency value between $0.8-0.99$, the production efficiency was second only to the frontier, with good range of factor input-output ratio allocation, including Rushan, Chiping and other 7 counties, accounting for about $21.57 \%$. The third category was the medium-efficiency region with efficiency value of decision-making unit between $0.6-0.8$, agricultural production efficiency in the range that can be improved, and the number of such cities and counties is large, including Guangrao, Zhangqiu, Shen and other 20 counties, accounting for $45.1 \%$. The last category is the low-efficiency region with efficiency value of below 0.60 , the number of less, and accounting for only $3.92 \%$.

In the counties and cities of "medium-efficiency region" and "low-efficiency region", the PTE of Shen County, Yucheng, Qingyun and other 6 counties was significantly lower. According to the adjusted input data, it can be seen that the number of agricultural technical service personnel and the level of peasants' skill (the number of agricultural labor force with the professional certificate/the number of persons employed in the primary industry) are relatively insufficient, which restricts the input in agricultural technology and leads to low PTE. These areas are mainly dominated by traditional farming, and the extensiveness of agricultural production is obvious. The input in agricultural energy consumption, fertilizer use, agricultural mechanization and other material input in 8 counties such as Guangrao, Lijin, Linyi and 
Table 4: TE, pure TE and SE values of each demonstration zone after adjusting input variables

\begin{tabular}{|c|c|c|c|c|c|c|c|c|c|}
\hline Country & TE & PTE & SE & $\begin{array}{l}\text { Returns to } \\
\text { Scale }\end{array}$ & Country & TE & PTE & SE & $\begin{array}{l}\text { Returns to } \\
\text { scale }\end{array}$ \\
\hline Wendeng & 1.00 & 1.00 & 1.00 & - & Decheng & 0.88 & 0.92 & 0.96 & IRS \\
\hline Rongcheng & 1.00 & 1.00 & 1.00 & - & Yucheng & 0.70 & 0.76 & 0.92 & IRS \\
\hline Rushan & 0.87 & 0.98 & 0.89 & IRS & Laoling & 1.00 & 1.00 & 1.00 & - \\
\hline Dongying & 1.00 & 1.00 & 1.00 & - & Linyi & 0.77 & 0.90 & 0.86 & IRS \\
\hline Hekou & 1.00 & 1.00 & 1.00 & - & Pingyuan & 0.64 & 0.82 & 0.79 & IRS \\
\hline Guangrao & 0.61 & 0.85 & 0.72 & DRS & Xiajin & 0.70 & 0.85 & 0.82 & DRS \\
\hline Lijin & 0.79 & 0.97 & 0.81 & IRS & Wucheng & 1.00 & 1.00 & 1.00 & - \\
\hline Daiyue & 1.00 & 1.00 & 1.00 & - & Qingyun & 0.56 & 0.65 & 0.85 & IRS \\
\hline Yishui & 1.00 & 1.00 & 1.00 & - & Ningjin & 0.82 & 0.93 & 0.88 & DRS \\
\hline Zhangqiu & 0.73 & 0.91 & 0.80 & IRS & Qihe & 0.73 & 0.76 & 0.96 & DRS \\
\hline Guanxian & 1.00 & 1.00 & 1.00 & - & Tengzhou & 0.72 & 0.79 & 0.90 & DRS \\
\hline inxian & 0.76 & 0.79 & 0.96 & DRS & Shizhong & 0.80 & 0.98 & 0.82 & IRS \\
\hline Yanggu & 0.76 & 0.86 & 0.88 & DRS & Shanting & 0.74 & 0.81 & 0.91 & IRS \\
\hline Dong'e & 0.79 & 0.91 & 0.86 & IRS & Taierzhuang & 0.79 & 0.83 & 0.95 & IRS \\
\hline Chiping & 0.83 & 0.93 & 0.90 & IRS & Xuecheng & 1.00 & 1.00 & 1.00 & - \\
\hline Gaotang & 1.00 & 1.00 & 1.00 & - & Pingdu & 1.00 & 1.00 & 1.00 & - \\
\hline Dongchagn & 0.74 & 0.87 & 0.86 & IRS & Laixi & 0.99 & 1.00 & 0.99 & IRS \\
\hline Linqing & 0.56 & 0.89 & 0.63 & DRS & Huangdao & 0.85 & 0.95 & 0.89 & IRS \\
\hline Juxian & 0.85 & 0.87 & 0.97 & IRS & Jiaozhou & 0.98 & 0.98 & 1.00 & IRS \\
\hline Linzi & 0.77 & 0.96 & 0.80 & DRS & Jimo & 1.00 & 1.00 & 1.00 & - \\
\hline Juye & 0.71 & 0.93 & 0.76 & DRS & Bincheng & 1.00 & 1.00 & 1.00 & - \\
\hline Shouguang & 1.00 & 1.00 & 1.00 & - & Boxing & 0.73 & 0.89 & 0.82 & IRS \\
\hline Fangzi & 0.76 & 0.91 & 0.83 & IRS & Zhaoyuan & 0.83 & 0.93 & 0.89 & DRS \\
\hline Changle & 0.72 & 0.76 & 0.69 & DRS & Kenli & 0.75 & 0.92 & 0.82 & IRS \\
\hline Zhucheng & 0.80 & 0.99 & 0.81 & IRS & Laizhou & 0.79 & 0.79 & 1.00 & IRS \\
\hline Lingxian & 0.73 & 0.91 & 0.81 & IRS & Average Value & 0.79 & 0.83 & 0.91 & - \\
\hline
\end{tabular}

Juye are obviously at a high level, but the production of SE is low, resulting in the low overall efficiency. These areas have a higher level of moderate-scale land management, but over-reliance on mechanization and chemicalization will also lead to decreased soil fertility, soil hardening and diminishing marginal returns and inefficient output. It can also be seen from Table 3 that there are 15 demonstration zones in the stage with stable return to scale, 12 in the stage with decreasing return to scale, 24 in the stage with increasing return to scale, indicating a big room for improving the overall level of input.

As a pioneer and demonstration zone of agricultural modernization, the national modern agricultural demonstration zones play an important role in improving the comprehensive efficiency, resource utilization, organization mode reform and security of important agricultural products. It is a key move to promote the modernization of agriculture with Chinese characteristics. Based on the empirical results above and the practical problems in the development of Shandong agricultural demonstration zones, having discussion in the following aspects.

Increase the input in agricultural science and technology and enhance the level of agricultural technology development: By analyzing the adjusted input data, we can see that the input in agricultural science and technology and in the mechanization, is the main driving force of the fifteen demonstration zones at the frontier of production. Therefore, advanced technical elements and transformation of agricultural scientific and technological achievements are the key to promote the development of modern agriculture. First, establish and improve the modern agricultural technology promotion system, forming a long-term cooperation mechanism combining "scientific research institutes + government agencies + leading enterprises + demonstration households", taking agricultural science research and service agencies as the main body of the agricultural extension service system, set up a science and technology platform integrating agricultural science and education, production and research, guiding farmers to enhance the level of scientific and technological production. Second, enhance the support of science and technology to improve the level of material and equipment. Integrate various types of agricultural science and technology resources, and actively explore the modern farming techniques, breeding technology, processing technology. Focusing on the agricultural production processes such as farming, cultivating, supporting, incubating, breeding, make all-round promotion of full-featured, technologically advanced, new intelligent agricultural production equipment to encourage a higher level of demonstration zone, 
and to achieve the whole production mechanization of staple grain crops, driving the material and equipment level of surrounding areas, ensuring high yield and efficient agriculture while improving quality and income. Third, gather agricultural science and technology talents, and cultivate new professional farmers. Solidly carry out the farmers' professional and technical training and continuing education system, establish special incentive mechanism, and focus on training large farmer households and agricultural cooperatives leaders. At the same time, build an agricultural talent information network platform, select the high-end agricultural talents, creating a modern professional farmer team with good technology, operation and management to speed up the transformation of agricultural production results.

Reasonably allocate resources to enhance the output efficiency of demonstration zones: The construction of the national agricultural demonstration zone faces different initial conditions, the various resource status, levels of economic development, modes of agricultural production and management make it hard to simply adopt one model. It is necessary to grasp the inherent laws, improve the input of factors based on the efficiency characteristics, and reform the institutional mechanisms to maximize the agricultural productivity. For the demonstration zones with lower PTE, we should give full play to the strategic support function of agricultural science and technology innovation system to agricultural modernization and agricultural economic growth, promoting improvement of agricultural efficiency by relying mainly on input of production factors and financial support to relying on scientific and technological innovation, modern material and equipment level and professional production reform, upgrading agricultural science and technology innovation ability and the core competitiveness of the demonstration zones. For demonstration zones with low SE and return to scale, we should change the concept of agricultural development, improve the internal management level through institutional reform. The construction of modern low-carbon agriculture, two types of agriculture, circular economy aims to improve the output decrease and ecological damage caused by the agricultural industrialization.

Optimize the agricultural production environment and enhance the construction level of demonstration zone: Through the analysis of the results in Section 3, discuss how to optimize the production environment. First, promote regional economic development and increase the per capita disposable income of farmers. Through agricultural industrialization, revitalizing rural land and collective assets, industrial nurturing agriculture, raising farmers' income level, broadening the channels of agricultural input and financing, and better responding to the "construction of agriculture farmer and rural area". Second, improve the urbanization level, and promote the orderly transfer of rural surplus labor. Promote the construction of new urbanization, improve the quality and capacity of development, so that the process of urbanization serves agricultural modernization and better plays a "transfer effect" and "demographic dividend." Third, strengthen the integration of agriculture-related funds, and reasonably promote the benefitingfarmers policy. Improve the agricultural input and financing mechanism in the demonstration zone, establish a sound fundraising mechanism and management system, strengthen the coordination of the use of financial funds.

According to the actual use of financial resources in different regions, reduce the efficiency loss of capital supply. Fourth, actively promote the reform of rural property rights system, improve the land transfer mechanism, implement farmers' land contract management rights, encourage farmers to develop a new pattern of modest-scale operation through exchanges, shares, custody and land consolidation. Fifth, improve the level of agricultural information via "Internet + agriculture" policy. Provide timely and reliable climate, environment, resources and other information to agricultural production by applying GPS, sensors and remote sensing technology, improving the early warning mechanism of agricultural disasters. Relying on cloud computing, Internet of things and large data and other information technology, construct an agricultural intelligent management system and food safety information platform to achieve the digital use of resources and integration of intelligent agricultural technology application, so as to improve the agricultural production efficiency and management level more accurately.

In this paper, the three-stage DEA model was used to analyze the agricultural production efficiency of 51 modern rural demonstration zones in Shandong Province. The results showed that the production efficiency values of demonstration zones have changed significantly at first and third stages, indicating that the environment effect and random error factor do have an important effect on the evaluation of agricultural production efficiency. Compared with the traditional DEA, the three-stage DEA model is more reasonable and accurate; based on the SFA regression analysis, it is found that the environmental factors such as farmers' income level, urbanization level, financial support level and rural informatization level have a strong influence on the redundancy of various factors. After eliminating environment effects and random factors, the number of demonstration zones in the frontier of production increases and the overall productivity is improved. The average TP rises from 0.79 to 0.83 , the average PTE rises from 0.90 to 0.91 , and the average SE rises from 0.88 to 0.90. Every demonstration zone must follow their own characteristics and policy-driven force, make rational allocation of agricultural production factors, enhance the level of agricultural technology, promote the reform of production methods, optimize the development environment, and enhance the efficiency of agricultural production as per local conditions. 


\section{Acknowledgments}

This work was supported by MOE (ministry of education in China) project of humanities and social sciences on youth fund project (Grant No. 12YJC790155), Shandong social science planning project (Grant Nos. 18CJJJ35, 17CCXJ09); and funded by visiting scholars from Shandong University of Science and Technology.

\section{References}

Abbas, P., Y.Z.H.Y. Hashim and H.M. Salleh: Cytotoxic effects and response surface optimization of solvent extraction of crude extracts from Aquilaria Subintegra Uninfected Branch. Sci. Herit. J., 2, $10-15$ (2018).

Ashraf, M.A., N.H. Hussin and M. Gharibreza: Studies on the removal of heavy metals from aqueous solution using immobilized Typha angustata L. Earth Sci. Pak., 1, 12-16 (2017).

Ayaz, T., A.M. Khattak and N. Ahmad: Supra soft R-separation axioms. Acta Sci. Malays., 2, 27-31 (2018).

Azratul, A.N.M.D., J. B. Akbar, B.Y. Kamaruzzaman, H.I. Sheikh, K.C.A Jalal and H.N. Faizul: Bio-monitoring selected heavy metal concentration in Nerita sp. collected from Tanjung Lumpur mangrove forest. Environ. Eco. Sci., 1, 04-07 (2017).

Banker, R.D. and R.C. Morey: The use of categorical variables in data environment analysis. Manage. Sci., 32, 1613-1627 (1986).

Chen, Y.Q.: Research on production efficiency and influencing factors of agriculture in Jiangxi Province. East. Chi. Econ. Manage., 30, 21 28 (2016).

Chuanlei, L., L. Guomin, H. Yuanfei and W. Guojun: Research on mental health status and the relationship between spiritual belief and self - harmony. Sci. Herit. J., 2, 16 -20 (2018).

Fahim, N.F. and Z.S. Sathi: Assessment of hepatoprotective activity of roots and barks of Achyranthes aspera in carbon tetrachlorideinduced hepatotoxicity in rats. Malays. J. Halal. Res., 1, 23-26 (2018).

Fang, $\mathrm{H} .:$ Research on technical efficiency of agricultural production: Based on calculation, discovery and explanation of province level. J. Agrotech. Econ., 1, 34-41 (2010).

Fare, R., C.A.K. Lovell and S. Yaisawarng: Derivation of shadow prices for undesirable outputs: A distance function approach. Rev. Econ. Stat., 75, 374-380 (1993).

Farrell, M.J.: The measurement of productive efficiency. J. Roy. Stat. Soc., 30, 253-281 (1957).

Fried, H.O., C.A.K. Lovell, S.S. Schmidt and S. Yaisawarng: Accounting for environmental effects and statistical noise in data environment analysis. J. Prod. Anal., 17,121-136 (2002).

Gao, Y., H.L. Zhan, Y.L. Zhao, S.J. Li and J. Jiao: Research on significance of national modern agriculture demonstration district. Chin J. Agr. Res. Reg. Plan., 37, 103-113 (2016).

Hanley, N. and D. Oglethorpe: Principles for the provision of public goods from agriculture: Modeling moorland conservation in Scotland. Land Econ., 74, 102-113 (1998).

Hasanov, S. and M.A. Nomman: Agricultural efficiency under resource scarcity in Uzbekistan: A data envelopment analysis. Bus. Econ. Hori., 4, 81-87 (2011).

Hashemi, N.: Recognizing the potential of sustainable use of pasture resources in south khorasan province with approach of carrying capacity. Environ. Eco. Sci., 1, 09-12 (2017).

He, Z.L.: Research on production efficiency and influencing factors of agriculture in China an empirical study based on three-stage DEA model. Rural Econ, 6, 48-51 (2015).

Howlader, M.H.K., M.N. Islam, S. Biswas, M.E. Uddin, A. Shila, M.Z. Haque and N. Mahmud: Salt tolerance of chili genotypes during germination and seedling growth. Malays. J. Halal. Res., 1, 01-07 (2018).

Ismail, B.S. and S.H. Haron: Heavy metal and insecticide distribution and accumulation at the Bertam Agricultural Watershed in Cameron Highlands, Pahang, Malaysia. Water Conserv. Manage., 1, 04-06 (2017).

Jamal, F., A.M. Khattak, G.A. Khan and S. Abdullah: Five separation axioms in quad soft non-linear structure. Acta Sci. Malays., 2, 1420 (2018).

Jiao, Y.: Evaluation research of agricultural production efficiency in Shandong province. Chin J. Pop. Resour. Environ., 12, 105-110 (2013).

Krasachat, W.: Organic production practices and technical efficiency of durian farms in Thailand. Procedia Econ. Fin., 3, 445-450 (2009).

Kuang, Y.F.: Technology efficiency, technology process, factor accumulation and China's agricultural economic growth. J. Quant. Tech. Econ., 1, 3-18 (2012).

Lin, J.Y.: Rural reforms and agricultural growth in China. Am. Econ. Rev., 82, 34-51 (1992).

Liu, Z.F. and C.H. Wang: Organic agricultural production efficiency based on a three-stage DEA model: A case study of Yang County, Shaanxi Province China Population. Resour. Environ., 7, 105-112 (2015).

Nasri, $\mathrm{H}$. and N. Bouaïcha: Blooms of toxic cyanobacteria in freshwater in Algeria. Water Conser. Manage., 1, $05-06$ (2017).

Radmanfar, R., M. Rezayi, S. Salajegheh and V.A. Bafrani: Determination the most important of hse climate assessment indicators case study: hse climate assessment of combined cycle power plant staffs. J. Clean WAS, 1, 23-26 (2017).

Ray, S.C. and A. Ghose: Production efficiency in India agriculture: An assessment of the post green revolution years. Omega, 44, 58-69 (2014).

Samad, M.S.N.A., M.M. Hanafiah, M.J.A. Hasan, N.F. Ghazali and S.N. Harun: Ratio of water withdrawal to availability in Kelantan watersheds, Malaysia. J. Clean WAS, 1, 40-44 (2017).

Souza, G.D.S.E. and E.G. Gomes: Improving agricultural economic efficiency in Brazil. Int. Trans. Oper. Res., 22, 329-337 (2015).

Tariq, W., S.Q. Hussain, D.A. Nasir, N. Tayyab, S.H. Gillani and A. Rafiq: Experimental study on strength and durability of cement and concrete by partial replacement of fine aggegate with fly Ash. Earth Sci. Pak., 1, 07-11 (2017).

Theodoridis, A., S. Hasanov and A. Abruev: Efficiency and productivity change analysis of cotton production in Uzbekistan. Outlook Agr. 43, 259 (2014)

Tian, $Z$. and F. Cheng: Research on the production efficiency of equipment manufacturing industry in the East Coastal areas of China based on three -stage DEA Model. J. Ind. Tech. Econ., 36, 13-20 (2017).

Wen, G.J.: Total factor productivity change in China's farming sector: 1952-1989. Econ. Dev. Cul. Chg., 42, 1-41 (1993).

Xiang T.D.: Research on regional carbon efficiency and total factor productivity in China based on a three-Stage DEA model. Econ. Survey, 1, 20-25(2017). 